\title{
ANALYSIS OF STRAY GRAIN FORMATION IN SINGLE-CRYSTAL NICKEL-BASED SUPERALLOY WELDS
}

\author{
J. M. Vitek ${ }^{1}$, S. S. Babu ${ }^{1}$, J-W. Park ${ }^{2}$, S. A. David ${ }^{1}$ \\ ${ }^{1}$ Oak Ridge National Laboratory; P. O. Box 2008; Oak Ridge, Tennessee 37831-6096, USA \\ ${ }^{2}$ formerly at Oak Ridge National Laboratory, now at Samsung Electro-Mechanics Co.; Suwon, Kyunggi-Do, Korea, $442-743$
}

Keywords: single crystals, welding, stray grains, repair

\begin{abstract}
The formation of stray grains during weld solidification of Rene N5, a single-crystal nickel-based superalloy, was studied. Experimental laser and electron-beam welds showed the extent of stray grain formation was sensitive to the welding conditions. It was also found that cracking is associated with the presence of stray grains, and cracks follow along the stray-grain high angle boundaries. Modeling was carried out to investigate the mechanism of stray grain formation and to predict the extent of stray grains as a function of welding conditions and location within the weld. The effect of crystallographic orientation was also taken into account. It was found that the mechanism of constitutional supercooling for stray grain formation explained all of the experimental results. Modeling based on this mechanism indicated that welding conditions would have a very important influence on the extent of stray grain formation while crystallographic orientation had only a minor influence.
\end{abstract}

\section{Introduction}

Advanced gas turbine engines require high operating temperatures in order to achieve acceptable process efficiencies. The demand for high operating temperatures has led to the extensive use of single-crystal nickel-based superalloys for engine components. By their very nature these components have a high intrinsic cost and the development of a weld technology that can repair worn or damaged components, as well as repair casting defects to improve yield is very desirable. Such a technology will allow for more efficient and economical use of expensive turbine engine components.

Conventional welding of nickel-based single crystals leads to abundant cracking and the formation of stray grains, i.e., new grains that destroy the original single crystal structure [1-3]. An example is shown in Figure 1. In fact, the cracking is associated with the stray grains in that the high angle stray grain boundaries act as preferred paths for crack propagation [2, 3]. In order to avoid cracking, alternate filler metals with inferior mechanical properties (due to reduced levels of the strengthening $\gamma^{\prime}$ phase) can be used [4]. Most recently, successful single-crystal crackfree welds have been obtained under special conditions where a unidirectional thermal gradient exists [5-8]. However, a more general weld repair technology that can be used under 3D welding conditions that yields properties comparable to the single-crystal base material has not yet been developed. It is the purpose of this paper to study the mechanism of stray grain formation during welding. In this way, the means for avoiding stray grains during weld repair can be successfully identified and the development of a repair technology can be advanced.

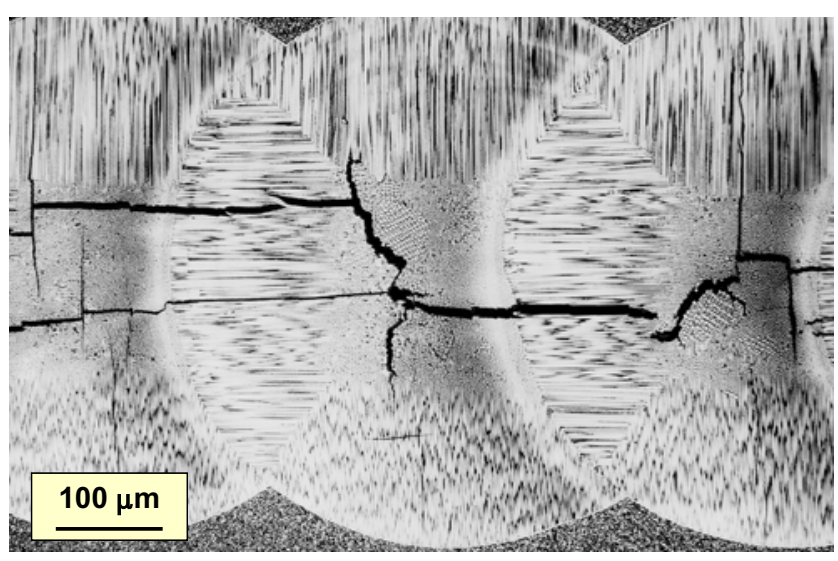

Figure 1: Pulsed laser weld of PWA 1480 single crystal nickel-based superalloy showing large regions of epitaxial growth as well as abundant stray grains and cracking along stray-grain high angle boundaries.

\section{Experimental Procedure}

Autogenous welds were made on $0.8 \mathrm{~mm}$-thick sheet of commercial Rene N5 single crystal using laser or electron beam welding processes. The composition of the alloy was (wt \%) Ni7.11Cr- 7.32Co- 6.25Al- 6.38Ta- 4.83W- 2.88Re-1.41Mo-0.15Hf$0.053 \mathrm{C}$. The welds were full penetration or nearly full penetration welds made on thin sheet that was electro-discharge machined from a single crystal slab. The crystallographic orientation of the sheet and weld direction were determined by Laue X-ray diffraction. For all welds, the sheet normal direction was [-0.925, $-0.376,0.051]$. For the laser welds, the welding direction was $[-0.141,0.217,-0.966]$ whereas for the electron beam welds, the welding direction was $[0.141,-0.217,0.966]$. The sheet normal deviated from the $[-1,0,0]$ direction by $15^{\circ}$ and the weld direction deviated from $[0,0,-1]$ (laser weld) or $[0,0,1]$ (electron beam weld) by $22^{\circ}$. It is important to note that the welds were made in such an orientation that the centerline was not a plane of (crystallographic) symmetry. This condition led to asymmetrical weld microstructures, as shown later. A range of conditions (power and speed) were used and these are shown in Table 1. The as-welded microstructures were evaluated by optical microscopy. In addition, the grain structure of the laser welds was analyzed by Orientation Imaging Microscopy (OIM) to clearly reveal the presence of stray grains and associated high angle grain boundaries. 


\section{Modeling Procedures}

Previous work analyzed the weld pool and its thermal properties using a finite element code [3]. That analysis allowed for a reasonably precise replication of the weld pool shape. However, the analysis procedure was numerically intensive and only a limited portion of the entire weld pool was evaluated in terms of dendrite growth behavior. In the present study, a less tedious, simpler thermal analysis was employed that allowed for a complete analysis over the entire weld pool surface. In this procedure, the Rosenthal solution for heat flow was utilized [9]. This analysis only considers conductive heat flow. Furthermore, a 3D thermal analysis was done. The actual weld cross sections were found to be intermediate between the $2 \mathrm{D}$ and $3 \mathrm{D}$ conditions in the Rosenthal analysis. The 2D case considers a weld pool that does not vary with depth, while the 3D case considers a weld pool that is only a partial penetration weld. While neither of these two simple cases accurately reflects the real cross-section of the welds, the $3 \mathrm{D}$ case was used because it has an inherent symmetry that allows for an integrated analysis over the entire weld pool surface that takes into account the variation in thermal parameters (thermal gradient and solidification front growth velocity) that is found in welds. Thus, the thermal modeling was more qualitative in nature, but it allowed for a thorough evaluation of trends that result from the variation in welding conditions. The same Rosenthal model has been shown to be effective in describing general behavior in other studies as well [10].

Table 1: Conditions Used for Experimental Welds

\begin{tabular}{|c|c|c|}
\hline Process & Speed $(\mathrm{m} / \mathrm{s})$ & Power $(\mathrm{W})$ \\
\hline Laser Beam & 0.0042 & 420 \\
\hline & 0.0127 & 804 \\
\hline & 0.0212 & 840 \\
\hline Electron Beam & 0.0042 & 250 \\
\hline & 0.0127 & 320 \\
\hline & 0.0212 & 612 \\
\hline
\end{tabular}

The simple Rosenthal 3D thermal analysis provided the basis for evaluating the thermal gradient and solidification front orientation over the entire weld pool surface. The weld pool surface was defined by the $1417^{\circ} \mathrm{C}$ isotherm, which is between the liquidus and solidus for the Rene N5 alloy. The thermal analysis was combined with a previously developed geometric model that identifies the dendrite growth direction in single crystal welds as a function of the initial sample orientation and weld direction [11, 12]. This combined analysis yielded a description of the dendritic growth conditions (thermal gradient, growth velocity) over the entire weld pool surface. Recently Gäumann et al have considered the nucleation and growth of crystals ahead of an advancing single crystal dendritic growth front [13]. Such nucleation and growth, due to constitutional supercooling ahead of the advancing solidification front, may lead to the formation of stray grains. The analysis of Gäumann et al was combined with the thermal analysis to determine the susceptibility of the nickelbased single crystals to stray grain formation during welding. As a result of the intrinsic symmetry of the Rosenthal solution, the susceptibility to stray grain formation could be integrated over the entire weld pool surface in a reasonable manner. The parameters used in the stray grain analysis were the same as those used by
Gäumann since their work was on a comparable nickel-based superalloy. Details regarding the modeling procedure are provided elsewhere [14].

\section{Results}

\section{Welding}

Representative optical micrographs of the laser and electron beam welds are shown in Figures 2 and 3, respectively. Figure 2a is a top-surface view of the slow-speed laser weld. Few stray grains were observed (shown more clearly in Figure 4a) and no cracking was seen. Figure $2 b$ is a higher magnification view at the fusion line. The perfect epitaxial growth from the base material can be seen. Since the growth during welding is much faster than during the original casting, the primary dendrite arm spacing of the weld is significantly finer than in the base material. Figure $2 \mathrm{c}$ shows a top-surface view of the medium speed laser weld. Cracking on one side of the centerline is evident. As shown in the higher magnification view of the centerline in Figure $2 \mathrm{~d}$, and in the transverse-view micrograph in Figure 2e, stray grain formation was fairly extensive. It is noteworthy that the extent of stray grains was significantly greater on the right side of the weld, the same side where the cracks were found. Similar results were found for the electron beam welds in Figure 3. Perfect epitaxy was found near the fusion line, especially in the slow-speed weld (Figure $3 b$ ), stray grains and cracking was asymmetrical with respect to the centerline (Figures $3 \mathrm{c}-\mathrm{e}$ ), and stray grains were more prevalent in the higher speed weld.

The highest speed welds were very similar to the medium speed welds for both laser and electron-beam welding. The results for all welds can be summarized as follows. First, stray grains were observed and their frequency varied dramatically with the weld process conditions. Second, the density of stray grains was asymmetrical with respect to the weld centerline. Third, cracking was observed in those welds with the highest density of stray grains, and the cracks followed along the high-angle stray grain boundaries. Moreover, the cracks were asymmetrical with respect to the centerline, in line with the fact that the stray grains density was asymmetrical with respect to the weld centerline. Finally, the higher-speed. higher-power welds were more prone to stray grain formation and to cracking, for both the laser and electron beam welds.

OIM analyses were only made on the laser welds. The results are shown in Figure 4 and the effect of welding conditions on the abundance of stray grains is clearly revealed. Nearly all of the grain boundaries shown represent misorientations of at least $10^{\circ}$. Although some stray grains are visible in the low speed, low power weld (Figure 4a), the higher speed, higher power weld (Figure $4 \mathrm{~b}$ ) shows significantly more stray grains. The stray grains are clearly asymmetrically distributed with respect to the centerline; many more stray grains were present on the right side of the weld. The stray grains also were concentrated near the centerline and were totally absent along the edge of the weld pool. Finally, the OIM analysis clearly shows that the cracks followed along the high-angle, stray grain boundaries. 

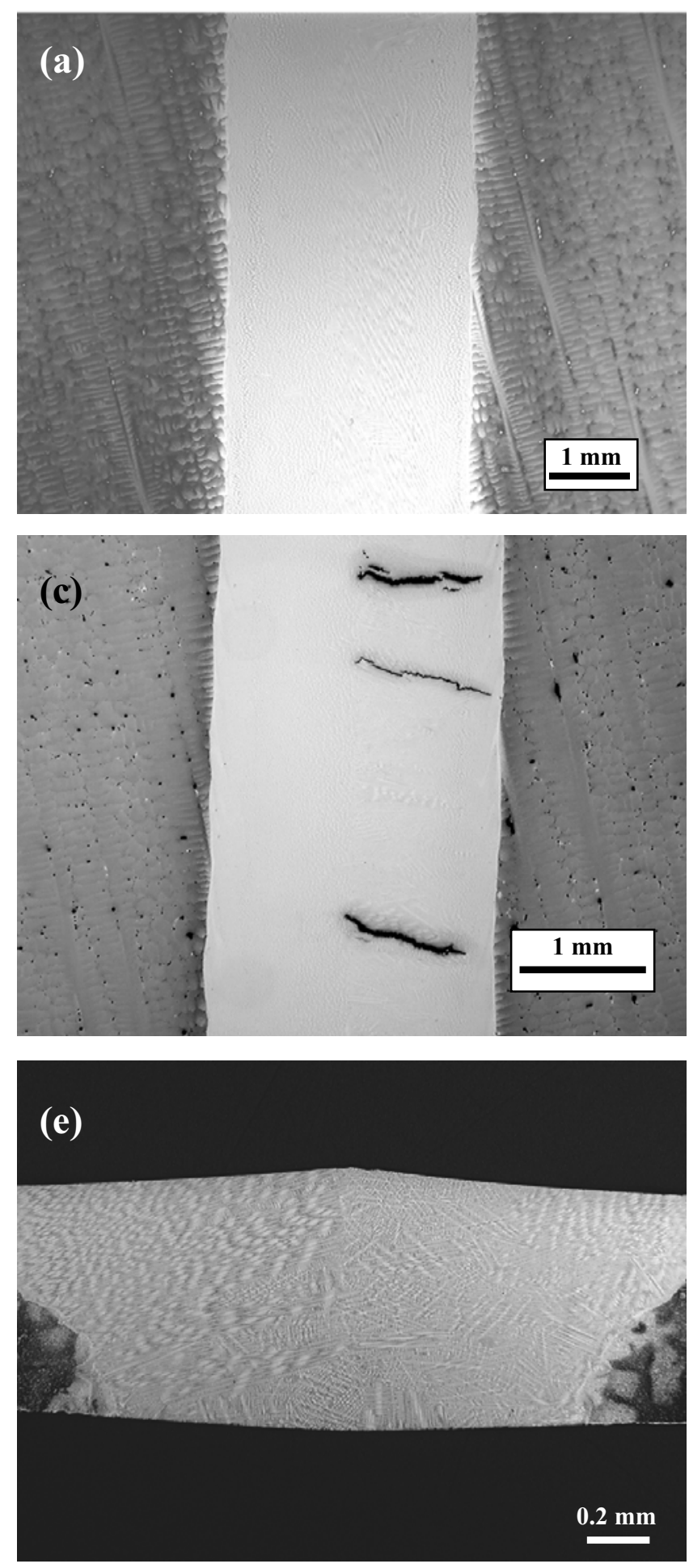

\section{Modeling}

In light of the experimental observations, it is argued in the next section that stray grain formation is controlled by the extent of constitutional supercooling ahead of the advancing solidification front, which results in the nucleation and growth of new grains. Based on this conclusion, modeling calculations were done to determine the extent of such nucleation and growth as a function of the welding conditions. The calculations were based on the
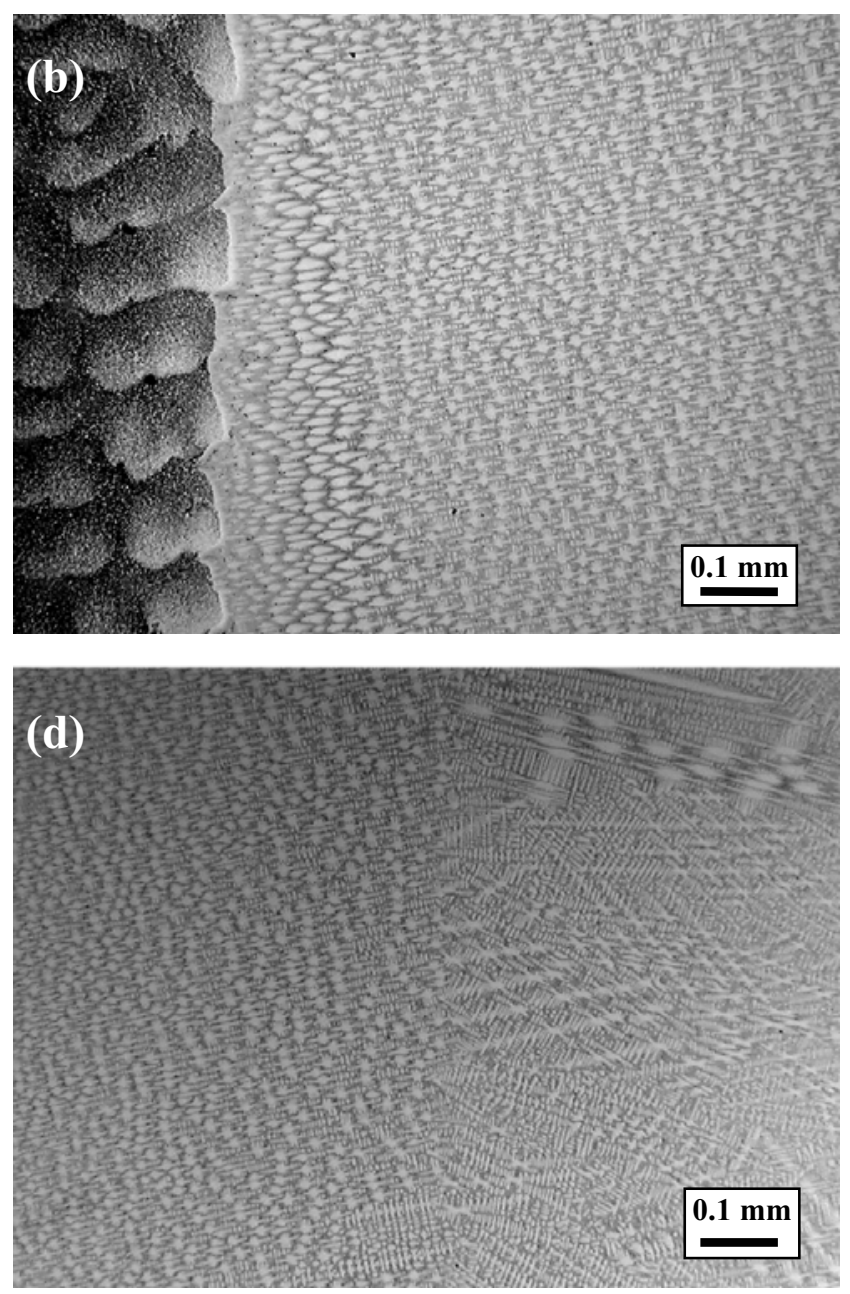

Figure 2: Optical micrographs of laser welded Rene N5. (a) top surface view of $0.0042 \mathrm{~ms}^{-1}$ weld, (b) higher magnification view of left side of (a), (c) top surface view of $0.0127 \mathrm{~ms}^{-1}$ weld showing asymmetrical stray grain distribution and cracking, (d) higher magnification view of centerline in (c), (e) transverse view of (c). Weld direction in a-d is from bottom to top.

simple Rosenthal thermal analysis and the theory originally proposed by Hunt [15] and further developed and applied to nickel-based superalloys by Gäumann et al [13].

The theoretical analyses of both Hunt [15] and Gäumann et al [13] consider a parameter $\Phi$ to describe the extent of nucleation and growth (stray grain formation) ahead of the advancing solidification front. $\Phi$ represents the volume fraction of equiaxed grains and varies from 0 to 1 . The value of $\Phi$ was calculated using the following equation, based on the derivation Gäumann et al [13]:

$$
\frac{\mathrm{G}^{\mathrm{n}}}{\mathrm{V}}=\mathrm{a}\left\{\sqrt[3]{\frac{-4 \pi \mathrm{N}_{0}}{3 \ln [1-\Phi]}} \frac{1}{\mathrm{n}+1}\right\}^{\mathrm{n}}
$$

where $\mathrm{G}$ is the thermal gradient, $\mathrm{V}$ is the growth velocity, a and $\mathrm{n}$ are material constants, and $\mathrm{N}_{0}$ is the nucleation density. The 

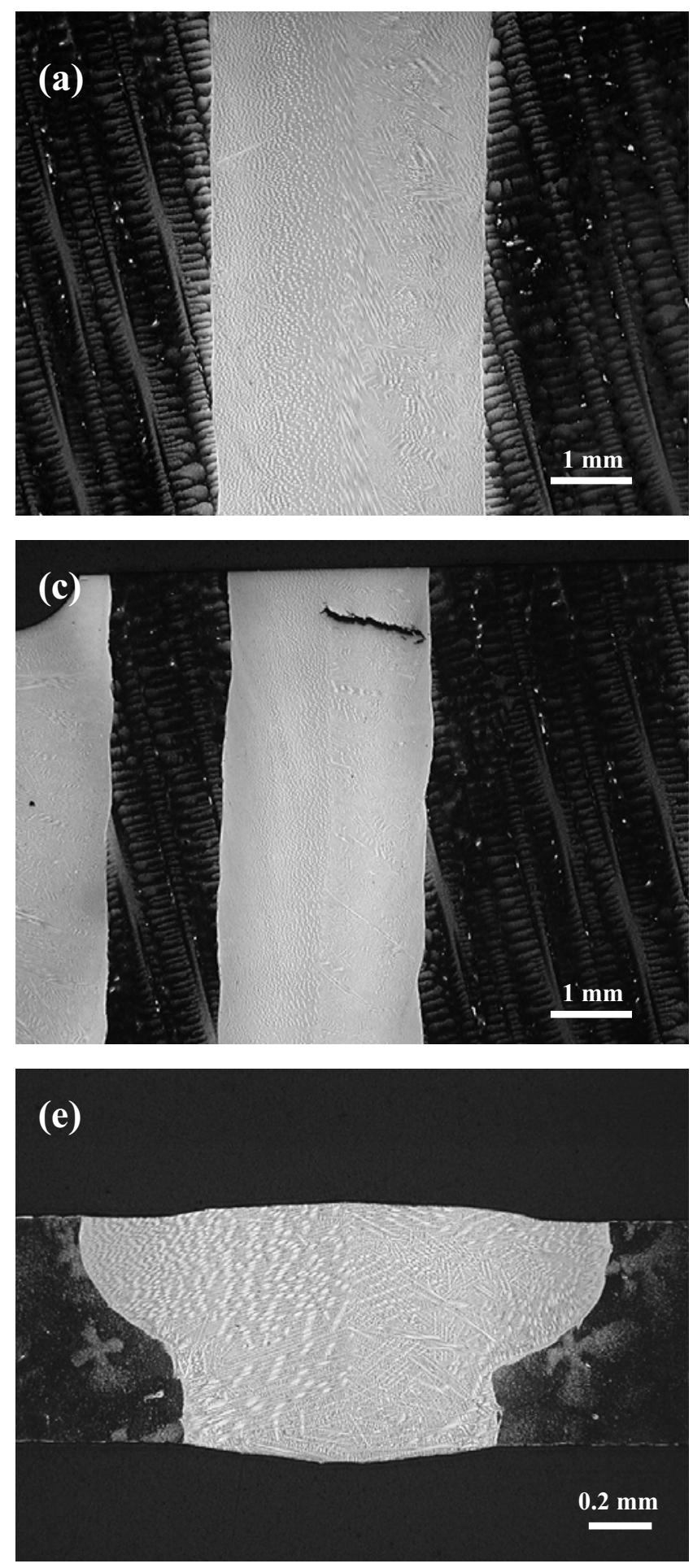

values for the three constants $\left(\mathrm{a}=1.25 \times 10^{6} \mathrm{sK}^{3.4} \mathrm{~m}^{-1}, \mathrm{n}=3.4\right.$, and $\mathrm{N}_{0}=2 \times 10^{15} \mathrm{~m}^{-3}$ ) were the same as those used by Gäumann for a similar nickel-based superalloy [13].

The equation is derived by considering the nucleation and growth of new crystals in the constitutionally supercooled region immediately ahead of the growing dendrites. In the derivation, the constitutional supercooling is given by the approximation $\Delta \mathrm{T}=$ $(\mathrm{aV})^{1 / \mathrm{n}}$ where $\mathrm{a}, \mathrm{V}$, and $\mathrm{n}$ have the same meaning as before. The
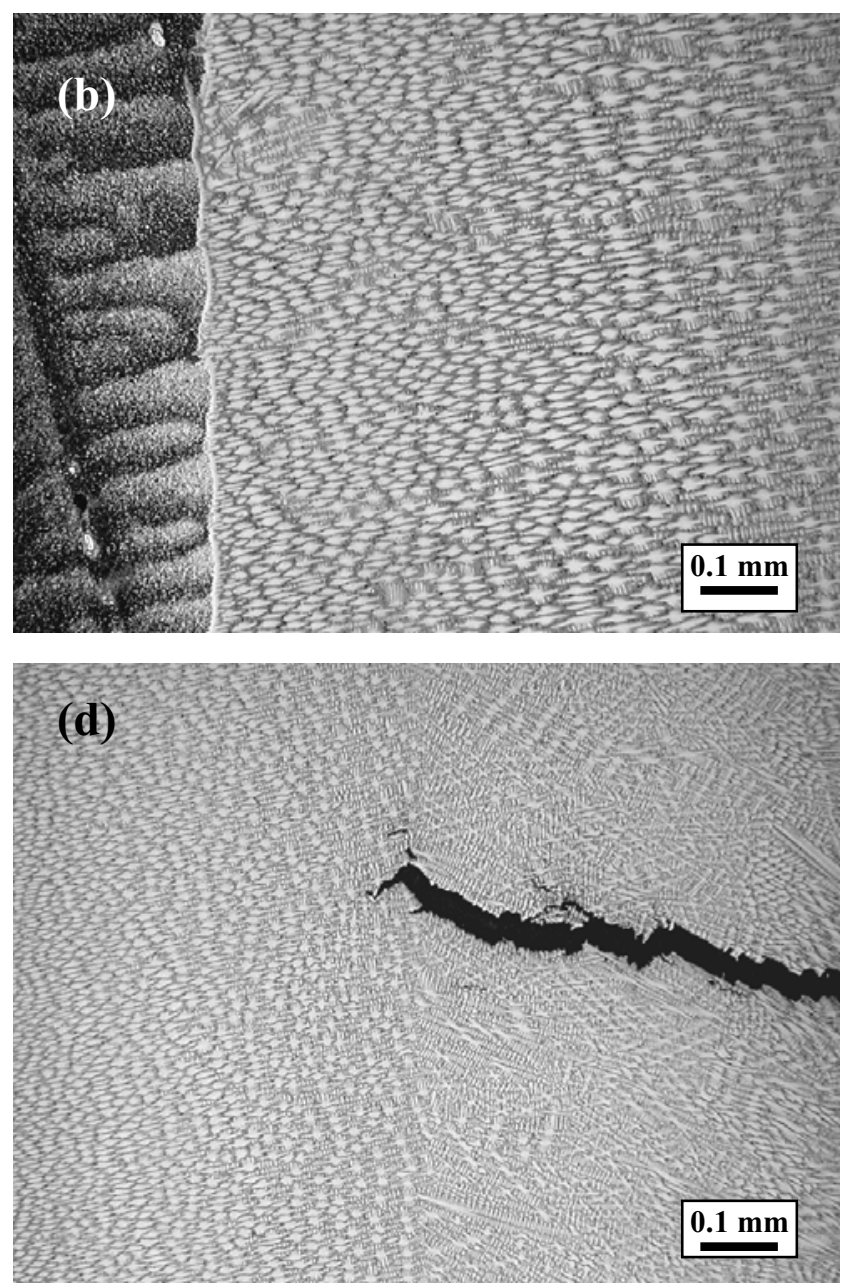

Figure 3: Optical micrographs of electron beam welded Rene N5. (a) top surface view of $0.0042 \mathrm{~ms}^{-1}$ weld, (b) higher magnification view of left side of (a), (c) top surface view of $0.0127 \mathrm{~ms}^{-1}$ weld showing asymmetrical stray grain distribution and cracking, (d) higher magnification view of centerline in (c), (e) transverse view of (c). Weld direction in a-d is from bottom to top.

derivation neglects curvature and thermal undercooling, which are small with respect to the constitutional undercooling. The nucleation undercooling is also ignored, which is assumed to be valid for high gradient conditions as those found under welding conditions [13].

When constitutional supercooling is minimal, $\Phi=0$ and no new grains form, yielding a weld microstructure that is free of stray grains and maintains is single crystal nature. When $\Phi=1$, the solidification is $100 \%$ equiaxed in nature. The critical value of $\Phi$ corresponding to a stray grain free microstructure was hypothesized to be $0.06[13,15]$. In the present work, rather than define a single critical value of $\Phi$, an overall average value of $\Phi$ $\left(\Phi_{\mathrm{AV}}\right)$, integrated over the entire weld pool solidification front, was evaluated and the variation of $\Phi_{\mathrm{AV}}$ as a function of welding conditions was determined. This approach is considered to be preferred to the use of a critical value since the analysis includes 

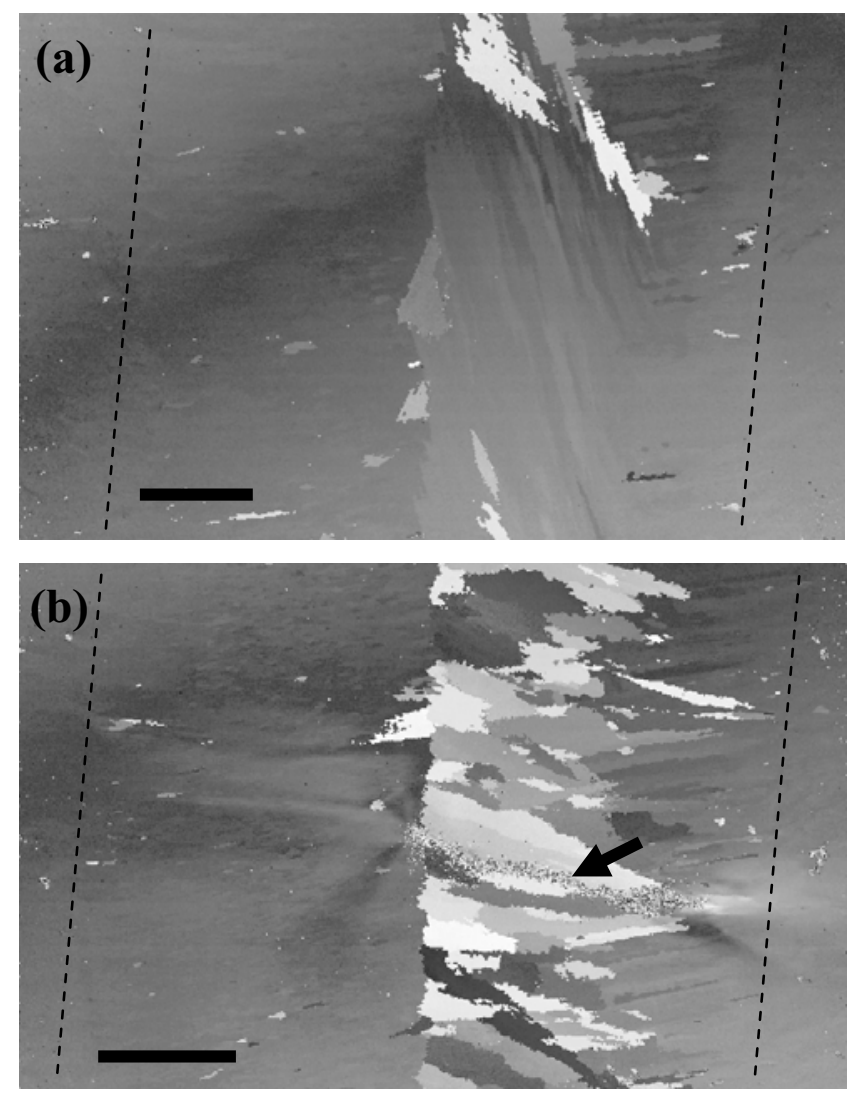

Figure 4: OIM micrographs of laser welded Rene N5. Top surface views of (a) $0.0042 \mathrm{~ms}^{-1}$ and (b) 0.0127 $\mathrm{ms}^{-1}$ welds. The dashed lines are approximate fusion zone boundaries and the weld direction is from bottom to top. The scale marker represents $0.5 \mathrm{~mm}$. The arrow points to a weld crack. Well-defined grain boundaries correspond to misorientations of $>10^{\circ}$.

several parameters that are not well-known, and the calculated absolute values for $\Phi$ may not be accurate. Regardless of the accuracy of the absolute value of $\Phi$, the changes in $\Phi_{\mathrm{AV}}$ as a function of changing conditions should be reliable.

When calculating $\Phi$ as a function of position, it is assumed that the dendritic growth is epitaxial with respect to the base material. Six possible dendrite growth variants are possible, corresponding to the six variants of the preferred [100] growth directions. All six possible growth direction variants are considered at each location. The growth direction that is selected at any given location is the one that is best aligned with the thermal gradient at that location, since this corresponds to a dendrite orientation with the minimum undercooling and the minimum growth velocity [11].

The area-weighted average value of $\Phi, \Phi_{\mathrm{AV}}$ (using the total area of the solidification front of the weld pool), was calculated and the results are plotted versus weld condition in Figure 5 for the three laser welding conditions in Table 1 . It can be seen that $\Phi_{\mathrm{AV}}$ is the lowest for the low speed, low power weld and is substantially higher for the other two welds. The asymmetry in the value of $\Phi_{\mathrm{AV}}$ with respect to the centerline can be shown in two ways. An area-weighted average of $\Phi$ was calculated for the left side versus

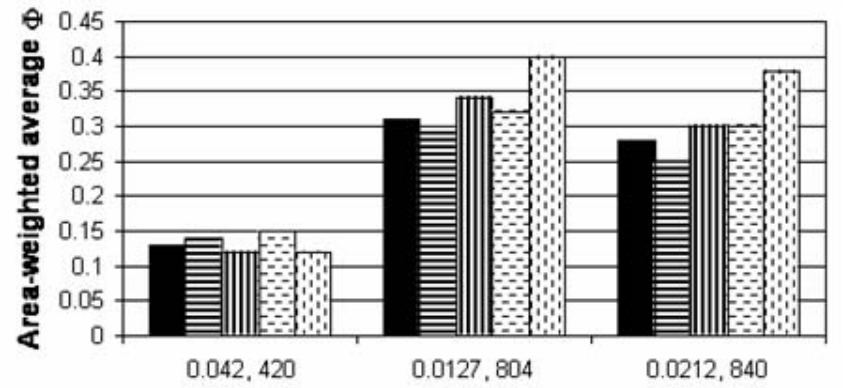

Conditions: speed $\left(\mathrm{ms}^{-1}\right)$, power $(\mathrm{W})$

Figure 5: Calculated values of $\Phi$, volume fraction of equiaxed grains, for three different laser welds. The solid bar is the area-weighted $\Phi$ over the entire weld pool surface, the solid horizontal and vertical striped bars are area-weighted $\Phi$ over the left and right sides of the weld pool, respectively, and the dashed horizontal and vertical striped bars are the average $\Phi$ over the top surface on the left and right sides, respectively.

right side of the weld, and these results are also included in Figure 5. In addition, since the calculations were for a $3 \mathrm{D}$ geometry but the laser welds were roughly full penetration welds, the average value of $\Phi$ across the solidification front on the top surface only was calculated for the left and right sides and these are also plotted in Figure 5. The results show that $\Phi$ is noticeably higher on the right side of the weld pool centerline for the two higherspeed, higher-power welds, indicating stray grains should be more abundant on the right side. This prediction is in perfect agreement with the experimental results presented earlier. It is interesting to note that for the low speed, low power weld, $\Phi$ is actually lower on the right side, but presumably the values of $\Phi$ are all low enough in this weld so stray grain formation is minimal everywhere. The calculations also showed that $\Phi$ is significantly greater near the centerline, again in agreement with the experimental results.

Finally, an analysis was made to determine the variation of $\Phi_{\mathrm{AV}}$ with the sample orientation. In addition to calculating the areaweighted average of $\Phi$ for the crystallographic orientation used in the experimental welds, $\Phi_{\mathrm{AV}}$ was also calculated for the same set of three welding conditions but for a few additional orientations. The results are shown in Table 2. These calculations show that the overall area-weighted average of $\Phi$ does not vary very much with sample orientation. The range in $\Phi_{\mathrm{AV}}$ values is negligible when compared with the variation in $\Phi_{\mathrm{AV}}$ due to the welding conditions.

Table 2: Variation of Area-Weighted Average $\Phi$ with Orientation

\begin{tabular}{|c|c|c|c|}
\hline $\begin{array}{c}\text { Orientation: } \\
\text { Weld direction, } \\
\text { surface normal }\end{array}$ & $\begin{array}{c}0.0042 \mathrm{~ms}^{-1} \\
420 \mathrm{~W}\end{array}$ & $\begin{array}{c}0.0127 \mathrm{~ms}^{-1} \\
804 \mathrm{~W}\end{array}$ & $\begin{array}{c}0.0212 \mathrm{~ms}^{-1} \\
840 \mathrm{~W}\end{array}$ \\
\hline Actual (see text) & 0.14 & 0.31 & 0.27 \\
\hline 100,001 & 0.14 & 0.31 & 0.27 \\
\hline 110,001 & 0.13 & 0.29 & 0.26 \\
\hline 100,011 & 0.14 & 0.31 & 0.27 \\
\hline $110,1-11$ & 0.13 & 0.29 & 0.26 \\
\hline 210,001 & 0.14 & 0.30 & 0.27 \\
\hline 310,001 & 0.14 & 0.31 & 0.27 \\
\hline
\end{tabular}




\section{Discussion}

There are two basic mechanisms that have been proposed to explain stray grain formation during solidification. The first is constitutional supercooling ahead of the advancing solidification front. Due to solute partitioning and the build-up of an enriched solute layer in front of the advancing solidification front, the liquid may be below its equilibrium liquidus temperature and nucleation and growth may take place. The second mechanism is that of dendrite fragmentation, where growing dendrites are broken, transported in the liquid, and then continue to grow at some other location with an orientation different from the original dendrite.

Dendrite fragmentation has been identified as the mechanism for forming many defects during casting of single crystal nickel-based superalloys. However, during welding the thermal and dendrite growth conditions are quite different than in casting. While convective flows are generally greater during welding, growth rates and thermal gradients are also significantly higher during welding. Many of the observations in the experimental welds do not conform to predictions based on the dendrite fragmentation mechanism. First, the extent of fragmentation should be symmetrical with respect to the weld centerline because fluid flow and the thermal behavior are symmetrical. However, the experiments clearly show that this is not the case. Second, dendrite fragmentation is expected to be more severe in regions where the cooling rates are highest [16]. Under welding conditions, the highest cooling rates are found along the edges of the weld, and the lowest cooling rates are along the centerline. The fact that stray grains are clearly more prevalent near the centerline indicates that they form where the cooling rates are lowest, again opposite to the predictions based on dendrite fragmentation.

In contrast, the experimental results agree very well with predictions based on the constitutional supercooling mechanism for stray grain formation. Model calculations in this work have shown that the extent of stray grain formation can be asymmetrical with respect to the weld centerline, and furthermore, the calculation predict more extensive stray grain formation on the same side as was observed experimentally. The constitutional supercooling mechanism also predicts stray grains will be more abundant near the weld centerline, again in agreement with the experimental results. Finally, calculations of the parameter $\Phi$ show that stray grain formation will be more extensive in the higher-speed, higher-power welds, as observed. Therefore, it is concluded that under welding conditions, the stray grain formation behavior is controlled by the extent of constitutional supercooling ahead of the advancing solidification front. Naturally, an alternate mechanism may apply under casting conditions, where the growth behavior is substantially different.

The model calculations show that the extent of stray grain formation should be significantly higher in the high-speed, highpower welds. A more detailed analysis of the effect of welding conditions on stray grain formation was done, using the same procedure as in this work [14]. In that study, the effects of welding parameters were examined. It was found that the welding parameters have a significant influence on the stray grain formation tendencies. The parameter $\Phi$, which is proportional to the extent of stray grain formation, varies with thermal gradient (G) and growth velocity (V) as $\mathrm{G}^{3.4} / \mathrm{V}$ for nickel-based superalloys [13]. Thus, the thermal gradient is far more important than the growth velocity in terms of avoiding stray grains. The more detailed analysis showed that the higher gradients obtained by changing the welding parameters have the most impact on reducing $\Phi$. The present experimental results confirm these theoretical predictions. The calculations also show that the effect of weld orientation is rather minimal in terms of stray grain formation. Thus, restrictions on weld repair operations in terms of the specific weld directions are negligible.

A simple, more qualitative constitutional supercooling analysis shows that the extent of constitutional supercooling is proportional to the solidification temperature range, $\Delta \mathrm{T}$. Thus, reducing $\Delta \mathrm{T}$ will help to avoid stray grains. This predicted relationship has been supported qualitatively in studies that have examined different types of single crystals and their behavior when welded [17]. The trends are summarized in Table 3, where the extent of stray grain formation is listed as a function of alloy and corresponding solidification temperature range. The table strongly suggests that a small solidification temperature range will help resist stray grain formation. Further work is currently underway to examine minor alloy modifications that may significantly reduce the rather large $\Delta \mathrm{T}$ in nickel-based superalloys and thus provide yet another means for limiting stray grain formation.

Table 3: Extent of Stray Grains as a Function of $\Delta \mathrm{T}$

\begin{tabular}{|c|c|c|}
\hline Alloy & $\begin{array}{c}\text { Solidification } \\
\text { Temperature } \\
\text { Range, } \Delta \mathrm{T}\left({ }^{\circ} \mathrm{C}\right)\end{array}$ & $\begin{array}{c}\text { Extent of Stray } \\
\text { Grains }\end{array}$ \\
\hline Pure Fe-15Cr-15Ni & $\sim 10$ & None \\
\hline $\begin{array}{c}\text { Impure Fe-15Cr- } \\
15 \mathrm{Ni}\end{array}$ & $\sim 20$ & Few \\
\hline Ni Superalloys & $\sim 40$ & Abundant \\
\hline
\end{tabular}

The results of the experimental and modeling work provide valuable insight into the potential for successful weld repair of nickel-based superalloys. "Successful" in this case means the resultant welds are free of stray grains, and associated cracks, while maintaining the high volume fraction of the gamma prime phase in order to maintain the excellent high temperature mechanical properties. The results show that welds with no cracks and minimal density of stray grains can be produced. Furthermore, the study indicates that fine tuning of weld conditions can lead to even better welds. Finally, with the identification of the mechanism of stray grain formation during welding as constitutional supercooling, further improvements to welding behavior may be achieved with judicial composition modifications that will reduce the solidification temperature range.

\section{Summary and Conclusions}

The solidification grain microstructure of single crystal nickelbased superalloy welds was investigated in the present study as a function of welding conditions. The experimental work was supplemented with modeling analyses to determine the extent of stray grain formation as a function of welding conditions. The investigation has led to the following conclusions:

1. The mechanism of stray grain formation is constitutional supercooling ahead of the advancing solidification front.

2. Stray grains were nearly absent in the low speed, low power weld, and no cracking was observed in this weld. 
3. Stray grains and associated cracks were more abundant in the higher-speed, higher-power welds.

4. The density of stray grains is greatest at the weld centerline. The distribution of stray grains depends on the crystallographic orientation of the weld, and they may be asymmetrically located with respect to the centerline.

5. While crystallographic orientation affects the distribution of stray grains, orientation plays a negligible role in terms of the overall density of stray grains.

\section{Acknowledgments}

This research was sponsored by the Division of Materials Sciences and Engineering, and the Advanced Turbine Systems Program, Office of Fossil Energy, U. S. Department of Energy, under contract DE-AC05-00OR22725 with UT-Battelle, LLC. The authors would like to thank General Electric Corporation for providing the Rene N5 alloy and PCC Airfoils Corporation for performing the chemical analysis.

\section{References}

1. S.A. David, J.M. Vitek, S.S. Babu, L.A. Boatner, and R.W. Reed, "Welding of Nickel-Base Superalloy Single Crystals," Sci. Technol. of Welding \& Joining, 2(2) (1997), 79-88.

2. J.M. Vitek, S.A. David, and L.A. Boatner, "Microstructural Development in Single Crystal Nickel-Base Superalloy Welds," Sci. Technol. of Welding \& Joining, 2(3) (1997), 109-118.

3. J.-W. Park, S.S. Babu, J.M. Vitek, E.A. Kenik, and S.A. David, "Stray Grain Formation in Single Crystal Ni-Base Superalloy Welds," J Appl Phys, 94(6) (2003), 4203-4209.

4. S. S. Babu, private communication with author, Oak Ridge National Laboratory, June, 2003.
5. M. Gäumann, S. Henry, F. Cléton, J.-D. Wagnière, and W. Kurz, "Epitaxial Laser Metal Forming: Analysis of Microstructure Formation," Mater. Sci. Eng'g., A271 (1999), 232-241.

6. W. Kurz, "Solidification Microstructure-Processing Maps: Theory and Application," Adv Eng'g Mater, 3(7) (2001) 443-452.

7. J.M. Vitek, unpublished results, Oak Ridge National Laboratory, 1998.

8. S. Krause, "An Advanced Repair Technique: Laser Powder Build-Up Welding," Sulzer Technical Review, 4 (2001) 4-6.

9. D. Rosenthal, "Mathematical Theory of Heat Distribution During Cutting and Welding," Weld J., 20(5) (1941), 220s-234s.

10. O. Hunziker, D. Dye, and R.C. Reed, "On the Formation of a Centreline Grain Boundary During Fusion Welding," Acta Mater. 48 (2000), 4191-4201.

11. M. Rappaz, S.A. David, J.M. Vitek, and L.A. Boatner, "Development of Microstructures in Fe-15Ni-15Cr Single Crystal Electron Beam Welds," Metall. Trans. A, 20A (1989), 1125-1138.

12. M. Rappaz, S.A. David, J.M. Vitek, and L.A. Boatner, "Analysis of Solidification Microstructures in Fe-Ni-Cr Single Crystal Welds," Metall. Trans. A, 21A (1990), 1767-1782.

13. M. Gäumann, C. Bezençon, P. Canalis, and W. Kurz, "Single-Crystal Laser Deposition of Superalloys: ProcessingMicrostructure Maps," Acta Mater., 49 (2001), 1051-1062.

14. J.M. Vitek, "The Effect of Welding Conditions on Stray Grain Formation in Single Crystal Welds," to be published, 2004.

15. J.D. Hunt, "Steady State Columnar and Equiaxed Growth of Dendrites and Eutectic," Mater Sci Eng'g, 65 (1984), 75-83.

16. T.M. Pollock and W.H. Murphy, "The Breakdown of Single Crystal Solidification in High Refractory Nickel Base Alloys," Metall Mater Trans A, 27A (1996) 1081-1094.

17. J. M. Vitek, S. S. Babu, S. A. David, and J-W. Park, "Microstructure Development in Single Crystal Welds," Mater Sci Forum, 426-432 (2003), 4123-4128. 
